\title{
12. ANÁLISE DOS ARTIGOS CONSTITUCIONAIS - DIREITOS FUNDAMENTAIS E A CONSTITUCIONALIDADE DA LEI DA COPA
}

\author{
Igor Rocha Almeida ${ }^{1}$ \\ Carla Eugênia Caldas Barros ${ }^{2}$
}

\begin{abstract}
RESUMO
Análise da Lei Geral da Copa - Lei 12.663/2012, que disciplina sobre as medidas relativas à Copa das Confederações FIFA 2013, à Copa do Mundo FIFA 2014 e à Jornada Mundial da Juventude 2013, que serão realizadas no Brasil, e estabelece concessão de prêmio e de auxílio especial mensal aos jogadores das seleções campeãs do mundo em 1958, 1962 e 1970. Trata-se também, de análise à diplomas correlatos, postos como suplementares. Perante um estudo de caráter crítico administrativo-constitucional, é verificado que o objeto em foco não se encontra totalmente de acordo com os mandamentos constitucionais, infringindo e não reconhecendo alguns de seus preceitos.
\end{abstract}

PALAVRAS-CHAVE: Análise crítica, Lei Geral da Copa, Mandamentos constitucionais, diplomas correlatos.

\begin{abstract}
Analysis of the World Cup General Law - Law 12.663/2012 that discipline about measures relating to the 2013 FIFA Confederations Cup, the 2014 FIFA World Cup and the 2013 Youth World Journey which will be hosted in Brazil, and establishes concession prize and special monthly assistance to players selections of world precepts champions in 1958, 1962 and 1970. Disciplines also, analysis correlated to the qualifications, submitted as supplementary. Facing a critical study of character administrative and constitutional, it is verified that the object in focus is not fully in agree with constitutional commandments, violating and not recognizing some of its precepts.
\end{abstract}

KEYWORDS: Critical analysis, World Cup General Law, Constitutional requirements, related laws.

\footnotetext{
${ }^{1}$ Bolsista de iniciação científica do PIBIC/ COPES/ CNPq 2012/2013, aluno da Graduação do 5o Período do Curso de Direito da Universidade Federal de Sergipe.

${ }^{2}$ Professora da Graduação e pós-graduação de Direito da Universidade Federal de Sergipe, coordenadora/ orientadora do projeto.
} 


\section{Introdução}

Eventos de caráter internacional serão sediados no Brasil, durante os anos de 2013 e 2014. E para tanto, o Poder Legislativo teve de editar uma Lex specialis que regulamentasse e estabelecesse diretrizes acerca da organização destes. Trata-se da Lei $12.663 / 2012$, que ficou conhecida por "lei geral da copa". Esta, não se restringe à regulamentação apenas da Copa do Mundo FIFA 2014, mas abarca também em seus presságios, disciplinamentos sobre a Copa das Confederações FIFA 2013, sobre a Jornada Mundial da Juventude 2013, que será também sediada no Brasil.

Além dos elementos já citados, a Lei que tratamos neste artigo estabelece uma concessão de um auxílio especial mensal e um prêmio em dinheiro aos jogadores da seleção de futebol brasileira campeã das Copas do Mundo de 1958, 1962 e 1970. Auxílios esses oriundos do orçamento do Ministério do Esporte, e da Previdência Nacional que serão administrados e pagos aos seus beneficiários pelo Ente da Previdência Nacional, ou seja, o INSS (Instituto Nacional da Seguridade Social). Se inclui também, nesta disciplina legal, pequenas alterações nas Leis $6.815 / 1980$ e $10.671 / 2003$, popularizadas como Estatuto do Estrangeiro e Estatuto do Torcedor, respectivamente.
A Lei em análise, ao regulamentar vários requisitos sobre a organização dos eventos, se divide em duas partes, tendo em vista sua vigência no tempo, a saber: disposições transitórias e permanentes. Transitórias porque ao cessarem os acontecimentos finais dos eventos, suas disposições perderão o objeto, fazendo com que automaticamente se revoguem, estando, inclusive, já previsto o prazo final de validade na própria lei. Em relação às Permanentes, estas continuarão válidas, por tempo indeterminado, como o próprio nome já traduz, até que sobrevenha outra lei que a revogue ou a modifique.

Eventos dessa magnitude, como exemplo da Copa do Mundo e das Confederações FIFA, são sempre realizados nos diversos países como uma parceria entre Poder Público e Privado, sendo que o real proprietário destes é pessoa jurídica de direito privado, in casu, a FIFA. A cooperação da Administração Pública em suas diferentes esferas da federação (Poder Municipal, Estadual e Federal), se dá por meio de garantia de serviços básicos e estruturais, simultaneamente, a exemplo da segurança externa aos eventos, de postos de plantões de saúde, de fácil tráfego da população ao longo das cidades, tanto no sentido de ida quanto no de volta dos eventos, da vigilância sanitária, da imigração temporária de estrangeiros, da alfândega, entre outros.

Todo um sistema logístico é montado, reestruturado, expandido, para 
atender aos requisitos básicos de infraestrutura, e por quaisquer falhas nesses setores já citados que gerem dano, a União será responsabilizada diretamente, e a FIFA, na medida em que concorreu à superveniência do mesmo. Percebe-se, ao verificar por inteiro as prelações da lei objeto deste estudo, uma excessividade de encargos a serem arcados pela União para o acontecimento dos eventos, e uma exagerada exclusividade da FIFA no tocante à venda de seus produtos nos locais e nos seus arredores próximos em que ocorrerão os mesmos. A União não receberá nenhum percentual do lucro gerado durante a realização dos eventos. Nota-se aqui, uma mitigação da razoabilidade e proporcionalidade na conduta da Administração Pública em seus atos discricionários, ao se submeter à certas exigências estabelecidas pela organização do evento. A negociabilidade em relação à esta parceria entre Administração Pública e o Poder Privado poderia ser colocada em diferentes tons.

\section{Copa das Confederações FIFA 1013 e Copa do Mundo FIFA 2014}

A Lei inicia seus presságios identificando cada órgão presente na organização dos eventos, sejam eles organizadores, coordenadores, ou meros colaboradores e prestadores de serviços terceirizados, que possuem autorização da FIFA (Federação Internacional de Futebol Associado / Federação Internacional Associada de Futebol). Dessa forma, toda a rede responsável torna-se conhecida e suas atribuições previamente destacadas.
Identifica também, na parte inicial referente às disposições preliminares, conceitos básicos e fundamentais sobre partida, período de competição, símbolos oficiais, dentre outros aspectos. Percebese que, neste primeiro momento, a Lei busca ir ao encontro dos conceitos padronizados pela FIFA, por ser a principal associação internacional de futebol e proprietária dos eventos.

Num segundo momento, passa a ser tratado sobre a proteção e a exploração de direitos comerciais. O INPI ( Instituto Nacional da Propriedade Industrial) é o órgão que fará as anotações cadastrais com as marcas titularizadas pela FIFA, entregues em lista, vale dizer, marcas de alto renome (que são conhecidas a nível mundial e que gozam de proteção especial), para fins de segurança contra a exploração ilegal e ilegítima de seus símbolos oficiais. A marca, segundo Barros (2007, p. 315):

Em termos de propriedade intelectual, é entendida como o conjunto de um ou mais sinais indicativos que individualiza determinado produto ou serviço, ou de um grupo deles, necessariamente associado a um empreendimento de qualquer natureza. Os elementos indicativos são constituídos, tipicamente, por nomes, imagens gráficas, até, em alguns países, sons, odores, etc. que se unificam na distinção de produtos ou serviços de um empreendimento ou, mesmo, do próprio empreendimento. 
Em tese, seguindo os ensinamentos do art. 124, inciso XIII, da Lei 9.279/1996, a Lei de Propriedade Industrial, não são registráveis como marca nome, prêmio ou símbolo de evento esportivo, artístico, cultural, social, político, econômico ou técnico, oficial ou oficialmente reconhecido, bem como a imitação suscetível de criar confusão, salvo quando autorizados pela autoridade competente ou entidade promotora do evento. No presente caso, é permitida a registrabilidade dos símbolos em função da solicitação desta última, sendo também permitida pela Lei Geral da Copa, de acordo com seu art. 4으, parágrafo único, que diz: "Não se aplica à proteção prevista neste artigo a vedação de que trata o inciso XIII do art. 124 da Lei no 9.279, de 14 de maio de 1996".

Há, aparentemente, um "conflito" entre essas normas ao vedar e permitir determinado registro, porém, a vedação a que o parágrafo único citado faz referência, se encontra na primeira parte do caput do inciso XIII, sendo que na sua segunda parte, já se torna permitida a registrabilidade quando se vale da expressão "salvo". Desfaz-se, assim, qualquer questionamento acerca do potencial "conflito" entre estas, inclusive no tocante aos registros de imitações suscetíveis de criar confusão, desde que os sejam autorizados pela autoridade competente ou entidade promotora do evento.

É previsto na Lei objeto desse estudo, um prazo especial de vigência da proteção às marcas titularizadas pela FIFA, prazo este de 30 meses, que expirarse-á no dia 31 de dezembro de 2014. O prazo ordinário é de 10 anos, prorrogável por períodos iguais e sucessórios, constante no art. 133 da lei 9.279/1996. Em virtude do acontecimento dos eventos, foram previstos na lei da copa, prazos reduzidos de exames, contestações, cancelamentos de pedidos de registros a serem vistos pelo INPI, e a aplicabilidade subsidiária da lei de propriedade industrial aos quesitos que não foram explicitamente tratados naquela lei.

Em seu art. 10, é previsto a isenção de pagamento por parte da FIFA, das retribuições referentes aos procedimentos realizados pelo Ente, durante a ocorrência dos eventos, ou seja, até o dia 31 de dezembro de 2014. Estes procedimentos e recursos previstos na Lei Geral da Copa, a serem realizados pelo INPI, foram simplificados, para atender à necessidade de resolução rápida de qualquer conflito ocorrente, sendo instituído um procedimento "sumário", ou mesmo "sumaríssimo". Disciplina também, a referida Lei, o preliminar indeferimento de pedidos de marcas que sejam cópias exatas ou similares (que causam confusão ou dúvida aos respectivos destinatários) às titularizadas pela FIFA.

Pela aplicação do brocardo lex specialis derrogat legi generali (lei especial derroga lei geral), poder-se-ia perceber a possibilidade da isenção de custas consagrada na lei da copa, porém, isso mitigaria com o princípio da isonomia, e com o referente ao acesso d̀ justiça, ambos consagrados constitucionalmente no art. 5으, caput, e inciso XXXV da CF. Excetuados os hipossuficientes (que não possuem condições financeiras de arcar com os encargos processuais, e mesmo, contrair advogados na defesa de seus direitos, 
protegidos pelo inciso LXXIV, do art 5o da $\mathrm{CF})$, há uma verdadeira quebra com ditos princípios, uma vez que nem os cidadãos brasileiros, em sua generalidade, nem as pessoas jurídicas de direito privado internas gozam desse privilégio $a b$ initio. Contraria também, com o da supremacia do interesse público, em virtude de que ao agir deste modo, põe o interesse privado num patamar superior ao público. Por mais que sejam procedimentos que não possuam um encargo financeiro grandioso, e, a contrario sensu, pelo forte poderio econômico possuído pela FIFA, conferir a isenção a esta, suas subsidiárias, ou prestadoras de serviços, configura abuso de poder, ilegalidade e desvio de finalidade, situações essas, plenamente passíveis de nulidade e responsabilização administrativamente de sua autoridade infratora, conforme salienta Meirelles (2011).

Inserido ainda no capítulo que trata da proteção e exploração comercial, são previstos, no art. 11 e seus parágrafos, áreas de restrição comercial e vias de acesso. Área de restrição comercial é a que se encontra ao redor dos locais oficiais de competição, nas suas imediações; e por sua vez, vias de acesso, são ruas, avenidas principais que conectam determinados pontos da cidade aos locais que sediarão os eventos, sendo imprescindíveis suas demarcações para acompanhamento, coordenação, orientação, e planejamento do tráfego ali incidente. Nesta parte, trata a lei de uma colaboração entre os Entes independentes da Administração Pública, através de seus órgãos internos e entes da administração indireta, a exemplo das Superintendências Municipais de Trânsito e Transporte Urbano, Ministério dos Transportes, dentre outros, com a finalidade de garantir uma maior organização na logística necessária para a perfeita realização destes eventos.

Trata também, da real exclusividade da FIFA, na exploração da publicidade, distribuição, vendas de suas marcas, produtos e serviços, bem como outras atividades promocionais ou de comércio de rua, garantidos pelo Poder Público local. Os limites à essas áreas de restrição comercial serão estabelecidos por autoridade competente, observando os requerimentos da FIFA ou de terceiros por ela indicados, tendo em vista um máximo de $2 \mathrm{~km}$ (dois quilômetros) ao redor dos locais oficiais de competição.

Através de um ângulo administrativo, nos é mostrado que, valendo-se dos princípios da razoabilidade e proporcionalidade, não é ponderável, razoável, ou mesmo proporcional, que o Poder Legislativo aja desta forma, ao conceder tamanha exclusividade à FIFA (pessoa jurídica de direito privado; multinacional) através da Lei em estudo. Segundo Lúcia Figueiredo (2006, p.50):

É por meio da razoabilidade das decisões tomadas que se poderá contrastar atos administrativos e verificar se estão dentro da moldura comportada pelo Direito.

São aplicáveis, no caso, normas de direito administrativo na crítica ao posicionamento do Legislativo, em função do caráter administrativo-vinculativo que essas regras consagradas possuem, uma vez que são normas de efeito concreto, 
ou seja, normas que ordenam certa atuação social por parte da Administração. Segundo Carvalho Filho (2011, p. 37):

Não custa lembrar, por outro lado, que o princípio da razoabilidade não incide apenas sobre a função administrativa, mas, ao contrário, incide sobre qualquer função pública, inclusive a legislativa. Por isso mesmo, o STF, por mais de uma vez, já declarou

a inconstitucionalidade de lei por violação ao princípio, [...], o que denota que esse tipo de ofensa afeta realmente o plano de validade dos atos.

Ao fixar determinados deveres específicos em lei, vincula-se a Administração Pública ao seu atendimento, sendo chamados esses de "deveres administrativos", conforme lições de Carvalho Filho (2011, p.41). Segundo Meirelles (2011 p. 122), haverá sempre aspectos sobre os quais a Administração terá opções na sua realização. A essas opções foi dado o nome de Poder Discricionário da Administração, poder que esta possui para agir com liberdade na escolha de seus atos, através de critérios de oportunidade e conveniência. E no caso em tela, foi entregue ao Poder Público competente, fixar os limites às áreas de restrição comercial nas imediações dos eventos. Dada a grandiosidade destes eventos e o aspecto logístico, áreas de diferentes tamanhos foram delineadas por todo o país, suprimindo muitas vezes o aspecto social nestes atos, que poderia ser considerado se houvesse uma maior organização por parte da Administração
Pública, como por exemplo, a realização de um cadastramento de vendedores "ambulantes" que possuam interesse em comercializar seus produtos nos contornos dos eventos, e a entrega deste cadastro à FIFA ou suas subsidiárias para reconhecimento e permissão da atuação destes.

Porém, o que restou percebido, então, foi uma notável submissão do Poder Público (Poder Executivo e Legislativo) às exigências formuladas pela FIFA, ao impedir a livre iniciativa do comércio de rua nas imediações dos eventos, e apenas permitir as atividades, dos estabelecimentos fixos que funcionam regularmente e que estão incluídos nessa área, desde que, de nenhuma forma se associem ou se assimilem aos Eventos Oficiais. Ocorreram no país vários protestos em virtude dessa restrição imposta pelos Poderes Públicos locais. Os comerciantes "ambulantes" foram às ruas na tentativa de que a Administração local permitisse que trabalhassem nas imediações dos eventos, a exemplo das vendedoras de acarajé (alimento típico vendido no comércio de rua), na cidade de Salvador, Bahia.

É mencionado no §2o do art. 11 da Lei em estudo, a seguinte preleção: A delimitação das áreas de exclusividade relacionadas aos Locais Oficiais de Competição não prejudicará as atividades dos estabelecimentos regularmente em funcionamento, desde que sem qualquer forma de associação aos Eventos e observado o disposto no art. 170 da Constituição Federal. Este artigo inicia o título "Da Ordem Econômica e Financeira", e em seus presságios, afirma a livre concorrência, conforme conclusões 
de Alexandre de Morais (2009, p.810), sobre o princípio, nos seguintes termos:

São princípios gerais da atividade econômica:

\section{$[\ldots]$}

Livre concorrência: constitui livre manifestação da liberdade de iniciativa, devendo, inclusive, a lei reprimir o abuso de poder econômico que visar à dominação dos mercados, à eliminação da concorrência e o aumento arbitrário dos lucros (CF, art. 173, §4ㅇ)

\section{[...] (MORAIS, 2009, p.810)}

Essa submissão revestida de "colaboração" deve ser cuidadosamente analisada para que não venha a se configurar abuso de poder. $O$ texto constitucional afirma ainda a livre iniciativa, o tratamento favorecido que deve ser dispensado às microempresas (ME's) e empresas de pequeno porte (EPP's), que sejam constituídas sob as leis brasileiras, dentre outros princípios. Além disso, seu parágrafo único e o art. 5ํㅡ. XIII, asseguram o livre exercício da atividade econômica, nos respectivos termos:

Art. 5ㅇ,

\section{$[\ldots]$}

XIII- "É livre o exercício de qualquer trabalho, ofício ou profissão, atendidas as qualificações profissionais que a lei estabelecer."

Art. 170,

\section{$[\ldots]$}

Parágrafo único. "É assegurado a todos o livre exercício de qualquer atividade econômica, independentemente de autorização de órgãos públicos, salvo nos casos previstos em lei."

A expressão "salvo nos casos previstos em lei", posta no parágrafo único do art. 170, torna possível a mitigação dos princípios acima citados, pois, como esta expressão não especifica o seu alvo, pode estar se referindo ao livre exercício da atividade econômica, como também, pode se direcionar para a independência ou não, de autorização dos órgãos públicos correspondentes. Caso este, que permitiu que a Lei Geral da Copa disciplinasse no sentido da mitigação dos referidos princípios, sendo, esta mitigação, vista por um olhar estritamente técnico, constitucional.

No tocante aos demais tópicos sobre a exploração dos direitos comerciais provenientes de seus eventos, a exemplo da captação de imagens e sons, radiodifusão, a Lei se encontra em plena adequação a estes, haja vista que os eventos são privados, e por essa razão, permitem a exploração, negociação, autorização e proibição de suas transmissões e retransmissões, consagradas na Lei. Segundo Lacerda Araújo: são medidas que procuram regulamentar direitos exclusivos de organizadores e patrocinadores oficiais dos eventos, coibindo a prática conhecida como marketing de emboscada. Na seção das sanções civis previstas, percebe-se a utilização do Código Civil como forma de norma disciplinar reparatória de violação de direitos em esfera cível, através de seu instituto "Das perdas e danos" (arts. 402 a 
405 da lei 10.406/2002), dentre outros institutos correlacionados.

\section{Prêmio e auxílio mensal aos jogadores das seleções de 1958, 1962 e 1970}

Adentrando no capítulo que trata sobre as disposições permanentes, o art. 37 o inaugura tratando sobre concessões de auxílios e prêmios aos jogadores, titulares ou reservas, da seleção brasileira de futebol vencedora das Copas do Mundo de 1958, 1962 e 1970. De acordo com seu inciso I e art. 38, é concedido: prêmio em dinheiro, no valor fixo de $\mathrm{R} \$ 100.000,00$ (cem mil reais) pago uma única vez. $E$, segundo o inciso II do art. 37: auxílio especial mensal para jogadores sem recursos ou com recursos limitados.

Nos seus artigos subsequentes, a Lei regula o modo no qual se dará estas concessões, tanto do prêmio quanto do auxílio-mensal, que órgão se responsabilizará por estas, hipóteses de cessação, transmissão, dentre outras. Embora o objetivo da medida seja o de recompensar os ex-jogadores da seleção brasileira pelo marco histórico que eles trouxeram, em virtude também da situação de miséria experimentada por alguns destes, a concessão do benefício pode estar eivada de inconstitucionalidade, o que, por este e outros motivos levou a PGR (Procuradoria Geral da República), na figura de seu Procurador-Geral, Roberto Monteiro Gurgel Santos, e de sua Vice-ProcuradoraGeral, Déborah Macedo Duprat de Britto Pereira, a entrar com uma Ação Direta de Inconstitucionalidade (ADI genérica), de no 4976, no STF (Supremo Tribunal Federal).

Primeiramente, em relação ao prêmio especial a ser pago, a Lei entrega ao Ministério do Esporte a competência para a realização do mesmo. A verba necessária ao pagamento do prêmio será extraída do Tesouro Nacional, devendo as despesas constarem, para custeio do benefício, de programação orçamentária do Ministério do Esporte. Ao se fazer uma leitura técnica sobre o assunto percebese que, o prêmio em dinheiro a ser concedido se enquadraria nos atos discricionários da Administração, porém, toda a discricionariedade deve ser pautada pelos princípios da legalidade, razoabilidade, proporcionalidade, pelo atendimento à critérios de oportunidade e conveniência, pois, caso contrário, deixaria de ser discricionariedade e se tornaria arbitrariedade, abuso de poder. Segundo ensinamentos de Carvalho Filho (2011, p.50):
Modernamente [...], os doutrinadores têm considerado os princípios da razoabilidade $e$ da proporcionalidade como valores que podem ensejar o controle da discricionariedade, enfrentando situações que, embora com aparência de legalidade, retratam verdadeiro abuso de poder."

E, novamente, afirma:

Verificando-se, pois, se a Administração agiu com equilíbrio no que diz respeito aos meios e fins da conduta, ou o fator objetivo da motivação 
não ofende algum outro princípio, como por exemplo, o da igualdade, ou ainda se a conduta era realmente necessária e gravosa em excesso.

Não há interesse público na concessão deste prêmio, o interesse é privado de seus beneficiários e familiares. A Administração proceder à doação deste prêmio é agir de forma desarrazoada aos seus fins precípuos, é instaurar uma política ainda mais assistencialista, criando uma dependência completa para com o Poder Público, é ferir ao princípio da igualdade, consagrado em nossa Constituição Federal, em seu art. 50, caput, primeira parte, que diz que todos são iguais perante a lei, sem distinção de qualquer natureza.

Fere ainda, o princípio da Supremacia do Interesse Público sobre o Privado, ao onerar a União com tamanhas despesas desnecessárias. Em seu art. 217 $C F$, que trata sobre o Desporto, não é previsto em nenhum de seus presságios a possibilidade da concessão deste prêmio a ex-jogadores, nem de forma indireta. Sobre o princípio da diferenciação do desporto profissional e do não profissional, consagrado no inciso III do art. 217, a Constituição se limitou a determinar tratamento diferenciado, e nas palavras de Van Holthe (2007, p.806), caracteriza-se 0 primeiro pela remuneração pactuada em contrato formal de trabalho, e o segundo pela liberdade de prática e pela inexistência de contrato. A Carta Magna apenas se refere, genericamente, ao incentivo à prática do esporte como dever do Estado, sua livre manifestação e organização, e disposições sobre a justiça desportiva.
Além de mitigar todos esses princípios, a Lei isenta o prêmio de pagamento de Imposto de Renda - IR e contribuição previdenciária. No decreto que regulamenta o IR, decreto $\mathrm{n}$ ㅇ 3.000/1999, não há previsão de exoneração de contribuição por prêmio percebido, e sim, em seu art. 2ㅇ diz:

As pessoas físicas domiciliadas
ou residentes no Brasil,
titulares de disponibilidade
econômica ou jurídica de renda
ou proventos de qualquer
natureza, inclusive
rendimentos e ganhos de
capital, são contribuintes do
imposto de renda, sem
distinção da nacionalidade,
sexo, idade, estado civil ou
profissão (Lei no 4.506 , de 30
de novembro de 1964, art. 10,
Lei no 5.172, de 25 de outubro
de 1966, art. 43, e Lei no 8.383 ,
de 30 de dezembro de 1991,
art. 4 o).

Em seu art. 39, que trata dos rendimentos isentos ou não tributáveis, não faz referência a prêmio desta natureza, conforme atestam seus incisos I ao XLVII, sendo, portanto, manifestamente ilegal determinada previsão na Lei da Copa, passível de sofrer controle de legalidade. Segundo Gurgel Santos (ADI 4976, p. 07), por mais que os atos históricos que foram alcançados pelos ex-jogadores sejam marcantes, não é justificativa suficiente para autorizar o pagamento a custo do erário de determinados valores.

Em relação ao auxílio mensal especial a ser pago aos ex-jogadores "sem recursos ou com recursos limitados" 
segundo expresso na lei, este sim, é previamente inconstitucional. Conforme anteriormente dito, de acordo com o art. 47 , as despesas decorrentes correrão à conta do Tesouro Nacional, e em razão disto, a previsão dos gastos deverá estar presente na programação orçamentária do Ministério da Previdência Social. A administração e o pagamento deste auxílio fica a cargo do INSS (Instituto Nacional da Seguridade Social), segundo o art. 44, devendo o Ministério do Esporte fornecer a devida lista de jogadores que a Lei se refere, para averiguação da plausibilidade dos requerimentos sobre o benefício.

Diz o art. 42, caput, que o auxílio especial mensal será pago para completar a renda mensal do beneficiário até que seja atingido o valor máximo do salário de benefício do Regime Geral da Previdência Social. $O$ teto do benefício salarial adotado no corrente ano, segundo Portaria recente do Ministério da Previdência Social e da Fazenda, corresponde ao valor de $\mathrm{R} \$ 4.159,00$ (quatro mil cento e cinquenta e nove reais), de acordo com reajuste de 6,20\% (seis inteiros e vinte décimos por cento), atualizado através do INPC (Índice Nacional de Preços ao Consumidor), medido pelo IBGE (Instituto Brasileiro de Geografia e Estatística).

Ao se ter conhecimento do valor máximo possível do benefício previdenciário que se pode ser auferido, percebe-se que além de inconstitucional, é extremamente desproporcional que o auxílio mensal especial corresponda a um valor dessa envergadura. A constituição prevê hipóteses taxativas da concessão do benefício previdenciário em seu art. 201, incisos I ao V:
Art. 201. A previdência social será organizada sob a forma de regime geral, de caráter contributivo e de filiação obrigatória, observados critérios que preservem o equilibrio financeiro e atuarial, $e$ atenderá, nos termos da lei, a:

1 - Cobertura dos eventos de doença, invalidez, morte $e$ idade avançada;

II - Proteção à maternidade, especialmente à gestante;

III - Proteção ao trabalhador em situação de desemprego involuntário;

IV - Salário-família e auxílioreclusão para os dependentes dos segurados de baixa renda;

$V$ - Pensão por morte do segurado, homem ou mulher, ao cônjuge ou companheiro $e$ dependentes, observado $o$ disposto no $§ 2$.

afirma:

Em seu §1으, expressamente

É vedada a adoção de requisitos e critérios diferenciados para a concessão de aposentadoria aos beneficiários do regime geral da previdência social, ressalvados os casos de atividades exercidas sob condições especiais que prejudiquem a saúde ou a integridade física e quando se tratar de segurados portadores de deficiência, nos termos definidos em lei complementar. 
A lei complementar, citada ao fim do referido parágrafo não foi devidamente viabilizada, o que permite dizer, momentaneamente, que o rol acima ainda é taxativo, isto é, as hipóteses de previsão da concessão de benefício devem se ater às traçadas no texto constitucional, e não um rol meramente exemplificativo (que permite outras situações além do texto constitucional ou legal). A taxatividade de alguns artigos significa limitações no atuar, não podendo criar novas situações além das previstas em lei. Diante do exposto, nota-se a impossibilidade de qualquer previsão legal de benefício de origem previdenciária diverso dos constantes e dos permitidos pelo texto atual da Constituição Federal. Esta se posiciona claramente sobre a temática, eivando de inconstitucionalidade a concessão prevista na Lei da Copa.

Mitiga-se, ainda, ao se instituir o auxílio especial, fins básicos da previdência social, pois, segundo o caput do art. 201, esta será organizada sob a forma de regime geral de caráter contributivo, o que não ocorre neste caso. Segundo Kertzman (2007, p.53), o princípio da tríplice forma de custeio da seguridade, ou seja, do custeio por parte do governo, empresas e trabalhadores, presente em nossa CF, faz parte de nossa história constitucional desde a Constituição de 1934. O art. 195, caput, preleciona:

"A seguridade social será financiada por toda a sociedade, de forma direta e indireta, nos termos da lei, mediante recursos provenientes dos orçamentos $d a$ União, dos Estados, do Distrito Federal e dos Municípios, e das seguintes contribuições sociais: [...]."

$E$, na segunda parte de seu inciso II, diz:

[...] "não incidindo contribuição sobre aposentadoria e pensão concedidas pelo regime geral de previdência social de que trata o art. 201."

A Lei da Copa não faz nem menção ao regime adotado de concessão do benefício, sendo considerado, caso fosse previsível constitucionalmente a hipótese criticada, criada nesta lei, o Regime Geral de Previdência Social, o RGPS. As normas que regulam o auxílio especial são normas de caráter previdenciário, que regulamentam as relações da seguridade social, e, a lei, ao prevê-lo, reconhece esse perfil. A Lei da Copa, em seu art. 46, o exclui do pagamento de contribuição previdenciária, por sua própria natureza de benefício previdenciário. Portanto, incidir previsão constitucionalmente estranha de benefício, seria se comportar contraditoriamente à Constituição, sem nexo relacional, o que, novamente, corrobora a impossibilidade jurídica desta disposição legal.

Ao, mais uma vez, se tratar do alcance jurídico do princípio da igualdade, preleciona, pari passu, Gurgel Santos (apud Bandeira de Mello, 2010 p.42):

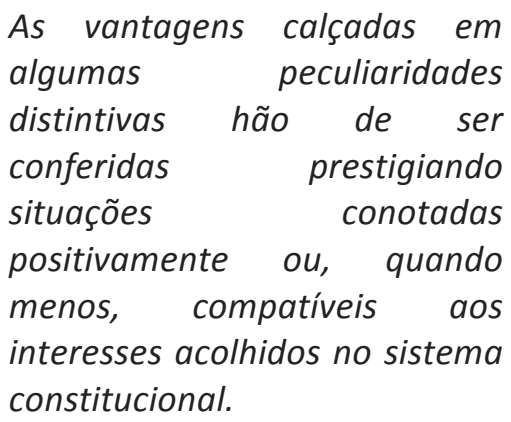

Reservadamente, não podem ser colocadas em desvantagem 
pela lei situações a que o

sistema constitucional

empresta conotação positiva. realizado por meio de convênio com os Estados, Distrito Federal e os Municípios, na forma da lei complementar.
A Assistência Social, consagrada no capítulo da Seguridade Social da atual CF, nos arts. 203 e 204, se destina a quem dela necessitar, independentemente de contribuição à seguridade social, e entre os seus objetivos, conforme preleciona os incisos do art. 203, possui:

\section{$[\ldots]$ \\ $V$ - A garantia de um salário mínimo de benefício mensal à pessoa portadora de deficiência e ao idoso que comprovem não possuir meios de prover à própria manutenção ou de tê-la provida por sua família, conforme dispuser a lei.}

A lei que o inciso acima faz referência é a lei no 10.741/2003, conhecida como Estatuto do Idoso. Norma de direitos especiais assegurados às pessoas com ou mais de 60 (sessenta) anos de idade. Este sim deveria ser o auxílio fornecido aos ex-jogadores da seleção brasileira. Por possuir previsibilidade constitucional, por se adequar à situação constante no texto da Carta Magna, e não ir de encontro ao sistema jurídico, aos seus princípios, suas finalidades. Afirma, ainda, José Afonso da Silva (2012, p.839), em referência ao art. 203 e seus incisos:

Além dessas hipóteses, ordenase que a União ainda institua programa de renda mínima destinado a assegurar a subsistência das pessoas e das familias, priorizando-se inicialmente as de baixa renda, podendo ser financiado $e$
Sobre a fonte pagadora, o caput do art. 204 da CF afirma que as ações governamentais na área da assistência social serão realizadas com recursos do orçamento da seguridade social, previstos no art. 195 da CF, além de outras fontes. Por meio desta previsão constitucional sobre a origem dos pagamentos, mais uma vez se comprova que a correta natureza do auxílio especial mensal seria a da assistência social, nos valores preconizados por esta, e não por uma arbitrariedade dos Poderes Executivo e Legislativo, que se direcionaram no interesse privado dos beneficiários e, principalmente, no alarme social feito pela mídia, através de suas redes televisivas, chamando a atenção para a situação de pobreza que alguns exjogadores se encontravam.

\section{Jornada Mundial da Juventude}

A Lei Geral da Copa possui pequenas remissões sobre a Jornada Mundial da Juventude. Nos artigos em que trata sobre sua organização, apenas se refere, genérica e subsidiariamente, aos que tratam do planejamento dos eventos FIFA como pressuposto de realização deste evento. Dada a complexidade e grandiosidade da Jornada Mundial, que será sediada no Rio de Janeiro, no corrente ano, é necessário um grande planejamento por parte do Poder Público, para que a exequibilidade do evento seja assegurada e possibilitada. A Administração Pública, ao colaborar com a realização deste evento, deve se ater às 
suas finalidades e não agir de forma incompatível com as mesmas, nem se subordinando às determinadas exigências, como foi feito perante a FIFA (e bastante criticada). Condutas que desatendam ao interesse público, que privilegiem certas entidades, que desrespeitem a soberania nacional, não devem ser postas em prática, pois desvirtuam os princípios da Administração, e sua forma legal de agir.

\section{Conclusão}

Tendo em vista toda a análise teórica realizada sobre a presente Lei, nos é mostrado que a mesma se encontra tomada de um vício chamado de inconstitucionalidade. Este vício a situa numa posição contrária à ordem jurídica, à jurisprudência, ao sistema legiferante, e até mesmo, à ordem social.

É posta em risco a própria ordem social, no momento em que a sociedade, mobilizada, unida e convencida de seus valores, opiniões e anseios, escolhe um determinado regime jurídico-políticosocial, que lhe trará segurança e satisfação. 0 Poder Legislativo, juntamente com o Executivo, que se manifestou no sentido de concordância e apoio ao comportamento expresso por aquele, atentaram contra a ordem jurídica e, inclusive, contra a soberania nacional, ao estabelecerem normas, "parcerias e colaborações" (faz-se referência aqui, aos gastos bilionários realizados pelo Poder Executivo, em suas três esferas, que comprometeram grande parte do erário atual) que expressam a plena submissão do governo aos desejos impostos e exigidos pela FIFA.
Ora, a FIFA, apesar de ser ente internacional de tamanha notoriedade, não pode fazer com que qualquer país (e isso não só é válido para o Brasil), atinja a sua soberania, ferindo-a, e desrespeitando seus mais ínfimos valores juridicamente protegidos. É andar de encontro ao Estado Democrático de Direito que foi arduamente alcançado por muitas nações, e ferir sua Lei Fundamental, base de todo um ordenamento jurídico posto e desenvolvido. Considera-se, assim, esta lei, parcialmente inconstitucional, e parcialmente passível de nulidade, de acordo com os fundamentos técnicos demonstrados, no âmbito do Direito Constitucional, Administrativo e demais ramos correlatos envolvidos.

\section{REFERÊNCIAS BIBLIOGRÁFICAS}

ARAÚJO, Nizete Lacerda. A Lei Geral da Copa e a Propriedade Intelectual. Disponível em: <http://www.clipnaweb.com.br/inpi/cons ulta/materia.asp?mat $=4660$ \&;

cliente=inpi\& $>$. Acesso em 21/06/2013.

BANDEIRA DE MELLO, Celso Antônio. Conteúdo Jurídico do Princípio da Igualdade. 3a Ed. São Paulo: Malheiros Editores, 2010.

BARROS, Carla Eugênia Caldas. Manual de Direito da Propriedade Intelectual. 1a Ed. Aracaju: Evocati, 2007

BRASIL, Lei no 12663/12, de 5 de junho de 2012. Brasília, 2012. Disponível em: <http://www.planalto.gov.br>. Acesso em 
BRASIL, Decreto no 3000/99, de 26 de março de 1999. Brasília, 1999. Disponível em: $\quad<$ http://www.planalto.gov.br>. Acesso em 22/05/2013.

BRASIL, Lei $n$ ㅇ 9279/96, de 14 de maio de 1996. Brasília, 1996. Disponível em: <http://www.planalto.gov.br>. Acesso em 15/04/2013.

BRASIL, Lei no 8213/91, de 24 de julho de 1991. Brasília, 1991. Disponível em: <http://www.planalto.gov.br>. Acesso em 14/06/2013.

BRASIL, Estatuto do Idoso, Lei no 10741/03, de 1o de outubro de 2003. Brasília, 2003. Disponível em: <http://www.planalto.gov.br>. Acesso em 18/06/2013.

BRASIL, Código Civil, Lei 10406/02 de 10 de janeiro de 2002. Brasília, 2002. Disponível em: $<$ http://www.planalto.gov.br>. Acesso em 29/04/2013.

BRASIL, Constituição Federal, de 5 de outubro 1988. Brasília, 1988. Disponível em: <http://www.planalto.gov.br>. Acesso em 21/02/2013.

CARVALHO FILHO, José dos Santos. Manual de Direito Administrativo. 24a Ed. Rio de Janeiro: Lúmen Júris, 2011.
KERTZMAN, Ivan. Curso Prático de Direito Previdenciário. 4a JusPODIVM, 2007.

LENZA, Pedro. Direito Constitucional Esquematizado. 15a Ed. São Paulo: Saraiva, 2011.

MACHADO, Carlos Augusto Alcântara. Direito Constitucional. Vol. 5. São Paulo: RT, 2005.

MEIRELLES, Hely Lopes. Direito Administrativo Brasileiro. 37ạ Ed. São Paulo: Malheiros Editores, 2011.

MORAIS, Alexandre de. Direito Constitucional. 24a Ed. São Paulo: Editora Atlas S.A., 2009.

SILVA, José Afonso da. Curso de Direito Constitucional Positivo. 35a Ed. São Paulo: Malheiros Editores, 2012.

STF, ADI 4976, de 17 de junho de 2013. Brasília, 2013. Disponível em: <http://www.stf.jus.br/portal/peticaolnici al/verPeticaolnicial.asp?base=ADIN\&s1=4 $976 \&$ processo $=4976>$. Acesso em 21/06/2013.

VAN HOLTHE, Leo. Direito Constitucional. 4a Ed. Salvador: JusPODIVM, 2008.

FIGUEIREDO, Lúcia Valle. Curso de Direito

Administrativo. 8a Ed. São Paulo: 